or with toxaemia due to massive miliary tuberculosis. ${ }^{10}$ Intrathecal hydrocortisone is effective in resolving impending spinal block and may dissolve existing blocks. The dosage recommended is $10 \mathrm{mg}$ with each intrathecal injection of isoniazid or streptomycin. Routine treatment with systemic or intrathecal corticosteroids is not recommended. ${ }^{1910}$ Freiman and Geefhuysen ${ }^{2}$ carried out a controlled trial under difficult conditions to determine the value of intrathecal streptomycin and hydrocortisone therapy, and though their study did not prove conclusively the value of intrathecal therapy it added to the existing evidence that its use is associated with better results.

Today we must expect recovery without sequelae in almost all patients who are conscious on admission as well as in many of the others. As intrathecal therapy is essential in some cases it is wise to give it initially to all patients, the routine course being 10 injections of streptomycin (10-50 mg per dose according to age). But longer or repeated courses should be given if necessary. Isoniazid (10-50 mg per dose according to age) and hydrocortisone (10-20 mg per dose) should be added in special circumstances, especially during relapse, or if there is a suspicion that the organism is getting less sensitive, or if spinal block is threatened. ${ }^{1}$ In late relapses or if there is no response to standard treatment the use of the new antituberculous drugs should be considered, especially rifampicin. ${ }^{6}$

In advanced cases much of the neurological damage and the intellectual retardation is due to the prolonged, high intracranial pressure leading to obstructive hydrocephalus. ${ }^{\mathbf{1 2}}$ This hydrocephalus can be relieved surgically while the child is still under systemic antituberculous therapy. All this implies long and formidable treatment, but the results justify it.

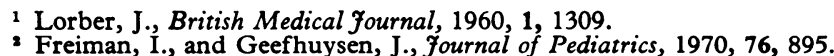

3 Illingworth, R. S., and W right, T., British Medical fournal, 1948, 2, 365.

- Illingworth, R. S., and Lorber, J., Archives of Disease in Childhood, 1956, $31,467$.

5 Canetti, G., le Lirzin, M., Porven, G., Rist, N., and Grumbach, F., Tubercle, 1968, 49, 367.

- Lorber, J., unpublished data.

Lincoln, E. M., Sordillo, S. R., and Davies, P. A., fournal of Pediatrics, 1960, 57, 807 .

Weiss, W., and Flippin, H. F., American fournal of the Medical Sciences, $1965,250,46$.

- Fitzsimmons, J. M., and Smith, H. M. V., Tubercle, 1963, 44, 103.

10 Hockaday, J. M., and Smith, H. M. V., Tubercle, 1966, 47, 75.

11 Miller, F. J. W., Seal, R. M. E., and Taylor, M. D., in Tuberculosis in Children, p, 416 . London, Churchill, 1963.

12 Lorber, J., Archives of Disease in Childhood, 1951, 26, 28.

\section{Platelet Transfusions}

The treatment of haemorrhage resulting from thrombocytopenia by the transfusion of fresh platelets is well established. But until recently platelet transfusion was reserved for the management of substantial haemorrhages. Technical advances have enabled fresh platelets to be more readily available than formerly, so that prophylactic platelet-replacement therapy is now possible. When sufficient quantities of platelet concentrates are available effective haemostasis can be maintained even in patients with very low platelet counts. Haemorrhages that would formerly have been fatal can now be averted, and operations can be carried out that would have been too hazardous without the concentrates.

Platelet transfusions are especially beneficial to patients in whom thrombocytopenia is the result of bone marrow failure. In aplastic anaemia haemorrhage is one of the main causes of death. ${ }^{1}$ Some patients suffering from this disease eventually recover their bone marrow function either spontaneously or as a result of treatment, and for them prophylactic platelet transfusions can successfully prevent bleeding attacks over long periods. ${ }^{2-5}$ Platelet transfusion can also be an essential support in the management of acute leukaemia. It helps to prevent haemorrhage both during periods of relapse and during $\stackrel{\odot}{\circ}$ the course of treatment with multiple chemotherapeutic. agents, many of which themselves cause severe depression of $\overrightarrow{\vec{F}}$ bone marrow. ${ }^{2-4}$ Similarly, patients with generalized malignant $\overrightarrow{0}$ disease can be treated with more intensive radiotherapy or $\underline{\bar{O}}$ chemotherapy if platelet transfusions are available to cover $\frac{\bar{\omega}}{\bar{\sigma}}$ the inevitable bone marrow depression.

In the thrombocytopenias associated with adequate or $\%$ increased numbers of megakaryocytes in the bone marrow, $\vec{\circ}$ when the platelet deficiency is presumed to result from their $\overrightarrow{\vec{\omega}}$ destruction by platelet antibodies (as in idiopathic thrombo- ${ }^{\omega}$ cytopenic purpura and the drug-induced immune thrombo- $\frac{5}{3}$ cytopenias), platelet transfusions are of less benefit to the patient. This is because the infused platelets are rapidly of removed from the circulation. However, a transient rise in numbers of platelets does follow transfusion of them in these $N$ patients, and this may be valuable in the management of $\frac{}{\triangle}$ potentially fatal haemorrhage or to allow a surgical operation $N$ to be done.

Platelets can be administered in the form of fresh plasma or as a concentrate. Dangerous spontaneous bleeding is rarely seen $^{6}$ if the platelet count is greater than $20,000 / \mathrm{mm}^{3}$. $\vec{\varphi}$ To raise adequately the platelet count in adults with a thrombo-.cytopenia of $10,000 / \mathrm{mm}^{3}$ or less platelets obtained from five blood donations are required. To maintain effective platelet levels in these adult patients requires the transfusion of platelets prepared from ten donors twice a week. Thus $\frac{\mathscr{Q}}{\Phi}$ platelet transfusions make expensive demands on the blood $\cong$ transfusion service. Plasmapheresis, at present available at a $\overrightarrow{\vec{O}}$ few centres, can economize in the provision of large quantities of platelets required for prophylactic transfusions. But unfortunately platelets do not store well under usual blood bank conditions, and they should preferably be used within six hours of their collection.

Even if the problem of supply is solved the effectiveness of long-term treatment with platelets is limited by iso- $\delta$ immunization. Many platelet antigens have been identified. ${ }^{7} 8$ Some appear to be restricted to platelets, while others are $\frac{}{3}$ shared with the leucocytes. Platelets almost certainly carry o antigens identifical to the histocompatibility (HL-A) antigens, $D$ but whether or not they share red cell antigens remains controversial. ${ }^{9-11}$ As platelet-rich plasma and platelet con- $N$ centrates are usually contaminated by red cells it is the practice to use, if possible, platelets prepared from donors of the same $\mathrm{ABO}$ and rhesus group as the recipient.

A practical platelet typing technique has yet to be developed, $\stackrel{\mathbb{\infty}}{\stackrel{\oplus}{+}}$ and selection of donors compatible with respect to platelet 0 antigens is not possible. Fortunately, in comparison with redo्? cells the antigenicity of platelets is low, and no naturally occurr- $\stackrel{\odot}{\odot}$ ing antibodies have been detected. However, repeated trans- $\stackrel{\mathbb{Q}}{\Omega}$ fusions of platelets prepared from a variety of donors over long periods invariably result in isoimmunization, with pro-8 gressively less satisfactory therapeutic responses. ${ }^{510}$ The HL-A antigens seem to be of primary importance. But a을 recent report ${ }^{5}$ has shown that, in patients who had become $?$ refractory to platelets from random donors, platelets obtained from siblings and matched for the main HL-A antigens have continually provided excellent clinical responses. Allergic and 
febrile reactions are occasional minor complications of platleet transfusion. There is, too, the risk of serum hepatitis.

1 Lewis, S. M., British Medical fournal, 1965, 1, 1027.

- Freireich, E. J., Transfusion (Philadelphia), 1966, 6, 50

- Flatow, F. A., and Freireich, E. J., New England fournal of Medicine, 1966, 274, 242 .

: Djerassi, I., Transfusion (Philadelphia), 1966, 6, 55. 73, 1 .

- Gaydos, L. A., Freireich, E. J., and Mantel, N., New England Fournal of Medicine, 1962, 266, 905.

Shulman, N. R., Marder, V. J., Hiller, M. C., and Collier, E. M., Progress in Hematology, 1964, 4, 222

- Dausset, J., and Tangun, Y., Vox Sanguinis, 1965, 10, 641

- Mollison, P. L., Blood Transfusion in Clinical Medicine, 4th edn., p. 354 Oxford, Blackwell Scientific, 1967.

10 Shulman, N. R., Transfusion (Philadelphia), 1966, 6, 39.

11 Aster, R. H., Blood, 1965, 26, 732.

\section{Cardiovascular Complications from Psychotropic Drugs}

Many drugs used for the treatment of depression have disadvantages and dangers which seriously limit their usefulness. The elating and habituating effects of the amphetamines together with their sympathomimetic activity render them undesirable for the young and potentially hazardous for any patients with cardiac disease. The monoamine oxidase inhibitors can cause fatal hypertensive crises if a restricted diet (poor in free tyramine) is not adhered to rigidly. Their inability to mix with other drugs lest hypertension or hypotension supervene and the risk of occasional hepatotoxicity further lower their worth.

The phencthiazines and tricyclic antidepressants are therefore widely prescribed, especially by doctors who are not specialists in psychiatry, for they are reputed to be relatively safe and suitable for the many patients for whom a trial of treatment with talk and tablet seems warranted before resort to the psychiatrist. Many patients are successfully maintained for years by these means. To the original phenothiazine, chlorpromazine, many later drugs have been added that are less likely to cause cholestatic jaundice and hypotension. Examples are trifluoperazine, promazine, and thioridazine. Among the dibenzazepine tricyclic antidepressants in common use are imipramine, amitriptyline, nortriptyline, trimipramine, and protriptyline. It is mainly from the psychiatrists that reports of adverse cardiac effects of these drugs have appeared.

The first sporadic reports of sudden death, cardiac dysrhythmias, disturbances of conduction, and electrocardiographic changes suggestive of infarction in patients on phenothiazine and imipramine-like drugs started to appear in 1963 and others have followed.1-4 Recently C. S. Alexander and A. Niño described disorders of this kind in seven patients who were under long-term treatment with large doses. ${ }^{5}$ Coronary artery disease seemed unlikely to be responsible for the cardiac changes because their patients, as well as those noted in previous reports, were mainly young.

The phenothiazines used in psychiatry (as distinct from related phenothiazines used in the treatment of Parkinsonism and others which have antihistamine actions) and the tricyclic antidepressants have similar actions with differing emphasis. Their psychotropic action is central and they also have hypotensive, adrenolytic, and atropine-like effects. The exact mode of action is ill understood, but high concentrations of catecholamine in blood and urine are thought to result from inhibition of tissue uptake of noradrenaline through competition for binding sites on the cell membranes. The high levels found are comparable to those accompanying phaeochromocytoma, and they are found even in patients who are hypotensive while on these drugs. ${ }^{6-9}$

In attempts at suicide with these compounds myocardial depression, dysrhythmias, conduction disturbances, and in the electrocardiogram a prolonged QT interval and depression of ST segment are described. Suggested antidotes are cholinergic drugs, neostigmine, or pyridostigmine. Beta-adrenergic blocking drugs have also been used.

The cause of the cardiac toxicity remains obscure. The increased plasma levels of catecholamine may be responsible for the dysrhythmias, for the complications of prolonged administration of the drugs are not unlike those of phaeochromocytoma. They include a "toxic cardiomyopathy", which may or may not be reversible. One of these compounds, thioridazine, is said to have quinidine-like activity, and that may account for the prolonged QT interval observed rather than the shortened interval which would be expected from excess catecholamine. Perhaps the raised plasma concentration of catecholamine together with the depletion of myocardial catecholamine which follows prolonged administration combine to determine the development of cardiac complications. Deposition of mucopolysaccharide in small arteries and arterioles has been found in the subendocardium of patients dying after many years of phenothiazine therapy, ${ }^{10}$ and Alexander and Niño found alterations in the ultrastructure of the myocardial mitochondria.

It would seem best to avoid prescribing these drugs for long periods whenever possible. In patients with heart disease, or if dysrhythmias or electrocardiographic changes appear, they should be replaced with psychotropic drugs from another group. When a tranquillizing agent is all that is needed the benzodiazepine group, chlordiazepoxide and diazepam, plus meprobamate and methylpentynol, are worth considering.

1 Kelly, H. G., Fay, J. E., and Laverty, S. G., Canadian Medical Association Fournal, 1963, 89, 546.

2 Schou, M., Acta Psychiatria Scandinavica, 1963, 39, Suppl. 169, p. 258.

3 Desautels, S., Filteau, C., and St.-Jean, A., Canadian Medical Association fournal, 1964, 90, 1030 .

- Leestma, J. E., and Koenig, K. L., Archives of General Psychiatry, 1968, 18, 137 .

S Alexander, C. S., and Niño, A., American Heart fournal, 1969, 78, 757.

- Alexander, C. S., and Niño, A., American Heart fournal, 1969, 78, 757. J. A., fournal of Pharmacology and Experimental Therapeutics, 1964, $144,196$.

Cairncross, K. D., Archives Internationales de Pharmacodynamie et de Therapie, 1965, 154, 438.

- Bahga, H. S., and Link, R. P., American fournal of Veterinary Research, $1966,27,81$.

- Carlsson, C., Dencker, S. J., Crimby, G., and Haggendal, J., Lancet, 1966, 1, 1208.

10 Richardson, H. L., Graupner, K. I., and Richardson, M. E., fournal of the American Medical Association, 1966, 195, 254.

\section{Special Groups in Tuberculosis}

Since tuberculosis in Britain is declining rapidly, measures for its control must be frequently reviewed to avoid wasting effort on unprofitable procedures. Already the use of massradiography has been altered to conform to the epidemio- 